\title{
Impact of armour layer on the depth of scour hole around side-by-side bridge piers under ice-covered flow condition
}

\author{
Mohammad Reza Namaee, Jueyi Sui* \\ Environmental Engineering Program, University of Northern British Columbia, 3333 University Way, Prince George, BC, Canada. \\ * Corresponding author. E-mail: jueyi.sui@unbc.ca
}

\begin{abstract}
In the present study, experiments were conducted in a large-scale flume to investigate the issue of local scour around side-by-side bridge piers under both ice-covered and open flow conditions. Three non-uniform sediments were used in this experimental study. Analysis of armour layer in the scour holes around bridge piers was performed to inspect the grain size distribution curves and to study the impact of armour layer on scour depth. Assessments of grain size of deposition ridges at the downstream side of bridge piers have been conducted. Based on data collected in 108 experiments, the independent variables associated with maximum scour depth were assessed. Results indicate that the densimetric Froude number was the most influential parameter on the maximum scour depth. With the increase in grain size of the armour layer, ice cover roughness and the densimetric Froude number, the maximum scour depth around bridge piers increases correspondingly. Equations have been developed to determine the maximum scour depth around bridge piers under both open flow and ice covered conditions.
\end{abstract}

Keywords: Armour layer; Local scour; Bridge pier; Ice cover; Non-uniform sand; Erosion of river-bed.

\section{INTRODUCTION}

Bed scour may be a natural occurrence or due to manmade changes to a river. Depending on the intensity of approaching flow for sediment transport, local scour process around bridge piers is classified as either clear-water scour or live bed scour. Local scour around bridge pier is a process of scouring as the result of installation of artificial obstacles such as weirs, abutments and piers in rivers (Richardson et al., 1993). More specifically, flow contraction in rivers caused by installation of hydraulic constructions such as bridge piers and abutments can lead to substantial local alteration of the flow patterns and significant increase of shear stress. As the result of increased shear stress around the hydraulic structures which is itself direct consequence of increased turbulence, flow velocities and the complex flow structures (downwelling, upwelling, horseshoe vortices) causes increased sediment entrainment at the river bed which eventually results in development of local scour holes (Török et al., 2014). The main feature of the flow around a pier is the system of vortices which develop around the pier. These vortex systems have been discussed by many researchers (Kothyari et al., 1992; Melville and Raudkivi, 1977; Melville and Sutherland, 1988; Raudkivi and Ettema, 1983, to mention only a few). One of the phenomena associated with characteristics of flow in the vicinity of bridge piers is the development of armour layer. Bed armouring process typically occurs in streams with non-uniform bed materials. This phenomenon occurs mainly due to selective erosion process in which the bed shear stress of finer sediment particles exceeds the associated critical shear stress for movement. As a consequence, finer sediment particles are transported and leave coarser grains behind. Through this process, the coarser grains get more exposed to the flow while the remaining finer grains get hidden among larger ones (Mao et al., 2011). Armour layer is also partially due to the reduced exposure of the flow with those sediments inside the scour hole zone (Sui et al., 2010). For the same bed sediments, Dey and Raika (2007) found that the scour depth around bridge piers with an armour layer is less than that without armour layer. Froehlich (1995) stated that the thickness of the natural armour-layer is up to one to three times the particle grain size of armour-layer. Raudkivil and Ettema (1985) found that due to the local flow structure around a pier, local scour may either develop through the armour layer and into the finer, more erodible sediment, or it may trigger a more extensive localized type of scour caused by the erosion of the armour layer itself. Sui et al. (2010) studied clear-water scour around semi-elliptical abutments with armoured beds. The results showed that for any bed material having the same grain size, with the increase in the particle size of armour-layer, scour depth will decrease. Török et al. (2014) investigated armour layer development in a scour hole around a single groin in laboratory. The main goal of their research was to study bed morphology, sediment transport, bed composition and hydrodynamics under conditions when bed armour development is expected. Guo (2012) studied the relevant scour mechanism of clear water scour around piers and proposed a scour depth equation. Zhang et al. (2012) studied bed morphology and grain size characteristics around a spur dyke. It was found that the mean grain size and the geometric standard deviation of the bed sediment are two important parameters in characterizing the changes of the bed morphologies and the bed compositions around the spur dyke. Kothyari et al. (1992) concluded that an increase in the geometric standard deviation of sediment gradation $\left(\sigma_{g}\right)$ would lead to a decrease in scour depth because of the armouring effect on the bed.

The presence of ice cover imposes a solid boundary to flow. The velocity profile under ice-covered condition is totally different compared to open channel flow. Under ice-covered condition, the maximum velocity occurs between channel bed and the bottom of the ice cover and is dependent on the relative roughness of these two boundaries (Sui et al., 2010). The velocity drops to zero at each boundary due to the no-slip boundary condition, resulting in a parabola-shaped profile (Zabilansky et al., 2006). The presence of ice cover has been found to increase local scour depth around bridge piers by $10 \%-\sim 35 \%$ (Hains and Zabilansky, 2004). Also, as pointed out by Wang et al. $(2015,2016)$, the appearance of bridge piers and abutments in channel has different impacts on ice accumulation under ice 
cover. Based on experiments in laboratory, Wu et al. (2014) claimed that with the increase in ice cover roughness, scour depth bridge around bridge abutments increased, correspondingly. The impact of ice on sediment transport in a stream is typically most significant during ice formation and breakup (Ettema and Kempema, 2012; Sui et al., 2000). Ice cover can either increase or decrease bed load and suspended sediment transport depending on the type of ice cover (Ettema and Kempema, 2012; Sui et al., 2000). Ettema et al. (2000) proposed a method for estimating sediment transport rate in icecovered alluvial channels. Wu et al. (2014) investigated the impact of ice cover on local scour around bridge abutment. Results show that with increase in densimetric Froude number, there is a corresponding increase in the scour depth. Results also showed that with increase in grain size of the armour layer, the maximum scour depth decreases and with increase in ice cover roughness, the maximum scour depth increases correspondingly (Wu et al., 2014).

Up to date, research work regarding the impact of ice cover on local scour in the vicinity of bridge piers is limited. In present study, three non-uniform sediments and two types of ice cover are used to study the development of armour layer in the scour hole around four pairs of bridge piers as well as to investigate the impact of ice cover and armour layer on the maximum scour depth under ice covered conditions.

\section{EXPERIMENT SETUP}

Experiments were carried out in a large-scale flume at the Quesnel River Research Centre of the University of Northern British Columbia. The flume is $38.2 \mathrm{~m}$ long, $2 \mathrm{~m}$ wide and $1.3 \mathrm{~m}$ deep, as showed in Figure 1a. The longitudinal slope of the channel bed was 0.2 percent. A holding tank with a volume of $90 \mathrm{~m}^{3}$ was located at the upstream of the flume to keep a constant discharge during each experimental run. To create different velocities, three valves were connected to adjust the amount of water into the flume. Two sand boxes were filled with natural non-uniform sediment. Theses sand boxes were spaced $10.2 \mathrm{~m}$ away from each other and were $30 \mathrm{~cm}$ deep and $5.6 \mathrm{~m}$ and $5.8 \mathrm{~m}$ in length, respectively. Three types of nonuniform sediments with different gain sizes were used in this experimental study. The natural non-uniform sediments had median grain sizes of $0.50 \mathrm{~mm}, 0.47 \mathrm{~mm}$ and $0.58 \mathrm{~mm}$ and the geometric standard deviation $\left(\sigma_{g}\right)$ of $2.61,2.53$ and 1.89 , respectively. According to Dey and Barbhuiya (2004), sediments used in this study can be treated as non-uniform since $\sigma_{g}$ is larger than 1.84. Four pairs of bridge piers with different diameters of $6 \mathrm{~cm}, 9 \mathrm{~cm}, 11 \mathrm{~cm}$ and $17 \mathrm{~cm}$ were used. Inside each sand box, a pair of bridge piers was placed symmetrically to the centre line of flume. The distance from the centre line of each pier to the flume centre is $25 \mathrm{~cm}$, as illustrated in Figure $1 \mathrm{~b}$.
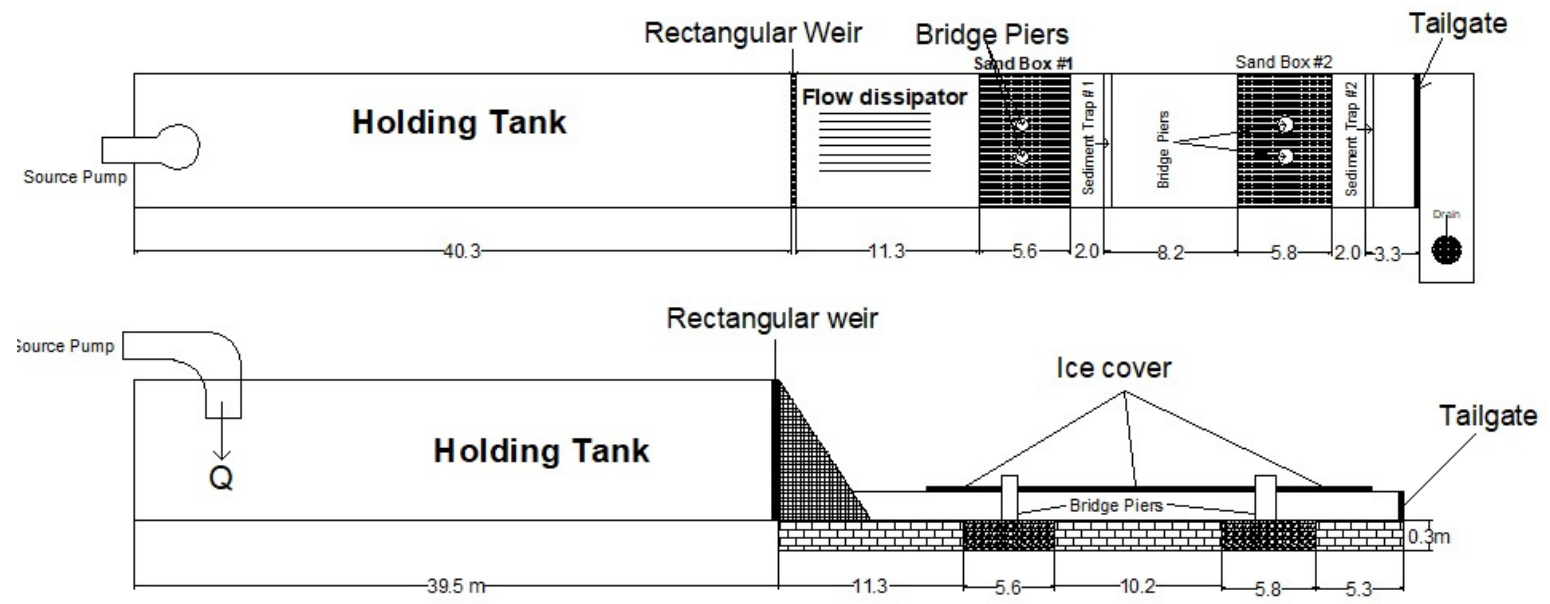

Fig. 1. Experimental setup. (a) Plan view and vertical view of experiment flume.

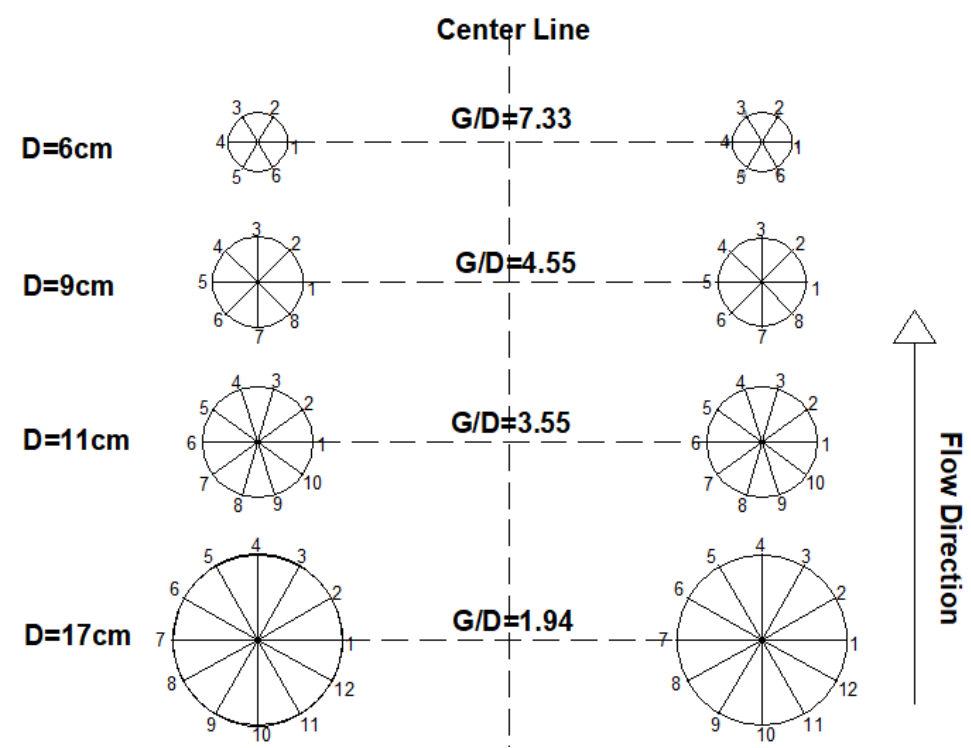

Fig. 1. Experimental setup. (b) The spacing ratio and measuring points around the circular bridge piers. 
Water level in the flume was controlled by adjusting the tailgate. In front of the first sand box, a SonTek incorporated 2D Flow Meter was installed to measure flow velocities and water depth during experiment runs. A staff gauge was also installed in the middle of each sand box to manually verify water depth. Velocity fields in scour holes were measured using a 10-MHZ Acoustic Doppler Velocimeter (ADV). The ADV is a highprecision instrument that can be used to measure 3D flow velocity in a wide range of environments including laboratories, rivers, estuaries, and the ocean (Cea et al., 2007). Styrofoam panels which were used to model ice cover, had covered the entire surface of flume. In present study, two types of model ice cover were used, namely smooth cover and rough cover. As showed in Figure 2, the smooth cover was the surface of the original Styrofoam panels while the rough cover was made by attaching small Styrofoam cubes to the bottom of the smooth cover. The dimensions of Styrofoam cubes were $2.5 \mathrm{~cm} \times 2.5$ $\mathrm{cm} \times 2.5 \mathrm{~cm}$ and were spaced $3.5 \mathrm{~cm}$ apart. A total of 108 flume experiments were completed under both open channel and ice-covered flow conditions. In terms of different boundary conditions (open channel, smooth covered and rough covered flow conditions), for each sediment type and each boundary condition, 12 experiments were done. Experimental runs were taken under clear-water scour conditions. After 24 hours, the flume was gradually drained, and the scour and deposition pattern around the piers was measured. To accurately read the scour depth at different locations and to draw scour hole contours, the outside perimeter of each bridge pier was equally divided and labeled as the reference points. The measurement of scour hole was subject to an error of $+/-0.03 \mathrm{~cm}$.

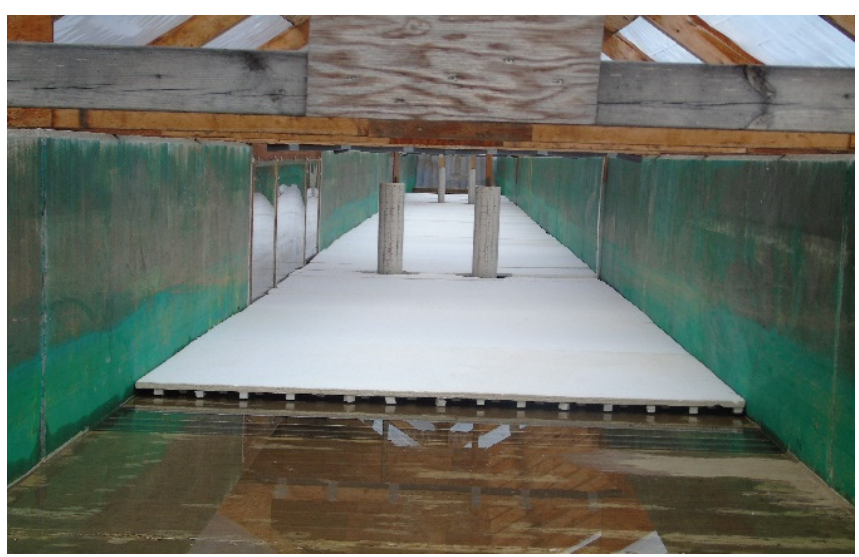

Fig. 2. Rough model ice cover on water surface.

After each experiment, sand samples within the scour hole which represent armour layer were collected. The samples were taken from the top layer of $5 \mathrm{~mm}$ of the armour layer in each scour hole. The sampling process is based on the sampling methodology for collecting armour samples proposed by Bunte and Abt (2001). The collected sand samples were eventually sieved and the mediums grain size of armour layer $\left(D_{50}\right)$ was calculated. The scour contours were also plotted by using Surfer 13, Golden Software. In present study, 108 Experiments (36 experiments for each sediment type) were conducted under open channel, smooth covered and rough covered conditions. For each sediment type, 12 experiments were done for open flow condition, 12 experiments for smooth ice-covered flow condition and 12 experiments for rough ice-covered flow condition, respectively. Flow depth in the flume was controlled by adjusting downstream tailgate. The flow depth ranges from $9 \mathrm{~cm}$ to $28 \mathrm{~cm}$. The flow velocity ranges between $7.0 \mathrm{~cm} / \mathrm{s}$ and $27.09 \mathrm{~cm} / \mathrm{s}$.

\section{RESULTS}

\section{Scour patterns and bed morphology}

Figure 3 shows the scour morphology and developed armour layer around the 17-cm-pier. Results indicate that the geometry of the scour holes under open flow condition is approximately similar to that under ice-covered flow condition. As shown in Figure 3, the armour layer covers the scour holes around bridge pier. At the downstream of bridge pier, a deposition ridge was developed. Figure 4 shows the scour contours and bed morphology around the 11-cm-pier under smooth covered flow condition for three different sediments. Under the same flow condition and ice-covered condition, the maximum scour depth occurs in channel bed with the finest sediment $\left(D_{50}=0.47 \mathrm{~mm}\right)$. Due to the horseshoe vortex system, the maximum depth of sour hole is located at the upstream face of the piers, and the scour hole extends along the sides of the piers towards the downstream face of the pier where the wake vortex exists. This scouring process around bridge piers is substantially due to the merging of the locally enhanced flow at the sides of the pier with the turbulent horseshoe vortices in front of the piers. Besides, sediment deposition ridge which is developed at the downstream of the piers, travels further downstream as vortex shedding occurs. Under the same flow condition and icecovered condition, as the sediment gets coarser, the turbulence of flow between the piers slightly decreases. Thus, with respect to Figure 4, a slight deposition which is caused by the jet-like flow has developed between piers, especially for channel bed with sediment of $D_{50}=0.47 \mathrm{~mm}$. Figure 5a shows the variation in scour depth elevation for 3 different sediments under smooth ice-covered flow condition, while Figure $5 \mathrm{~b}$ shows the variation in scour depth elevation for sediment of $D_{50}=0.58 \mathrm{~mm}$ under conditions of open channel, smooth ice-covered and rough icecovered flows. The following results are obtained from the Figure $5 \mathrm{a}$ and Figure $5 \mathrm{~b}$ :

Under the same boundary condition (either covered flow or open flow), the maximum scour depth is located at the upstream nose of the pier (at point 9 of the 11-cm-pier as showed in Figure 1b). The primary horseshoe vortex which is stronger at the front face of pier is responsible for this. As confirmed by Muzzammil and Gangadhariah (2003), the primary horseshoe vortex which generates in front of a pier is the main reason for scour over the entire scouring process. Results showed that the interaction between the primary horseshoe vortex and the finer sediment is more intense than that of coarser sediment. Also, the lowest scour hole is located at point 4 which is behind the pier as showed in Figure 5a.

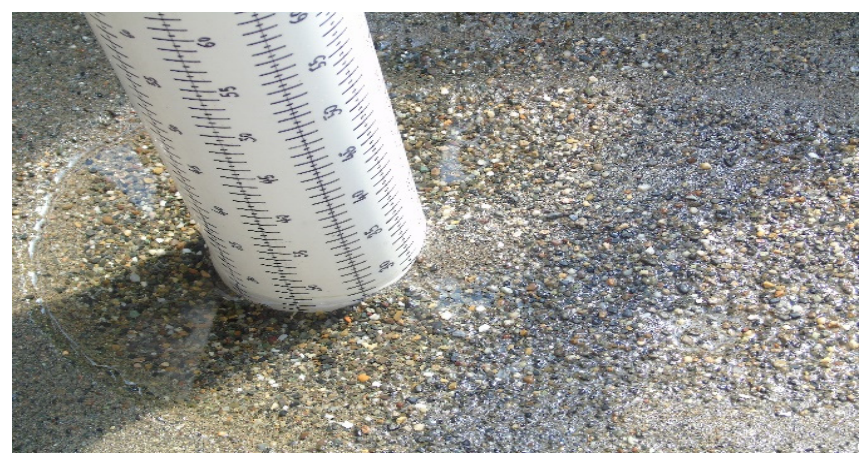

Fig. 3. Armour layer developed around the 17-cm-pier. 


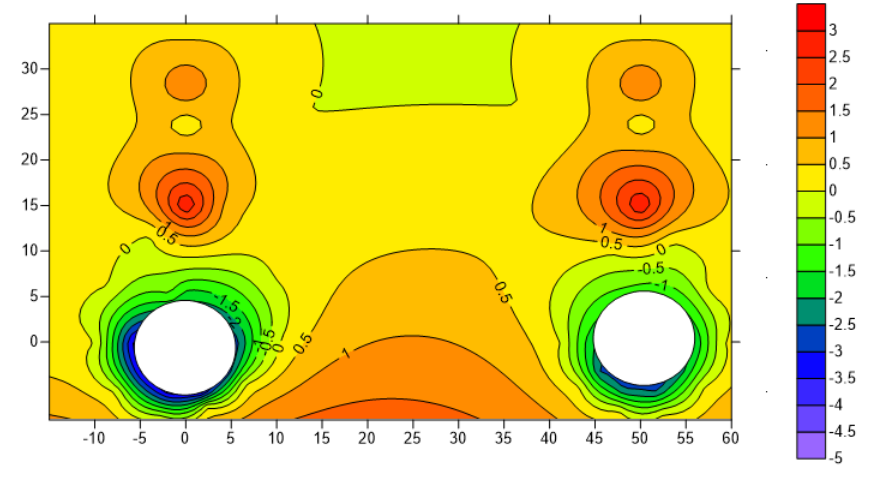

Fig. 4a. Scour morphology and the deposition ridge around the 11 -cm-pier under smooth ice-covered condition for $D_{50}=0.50 \mathrm{~mm}$.

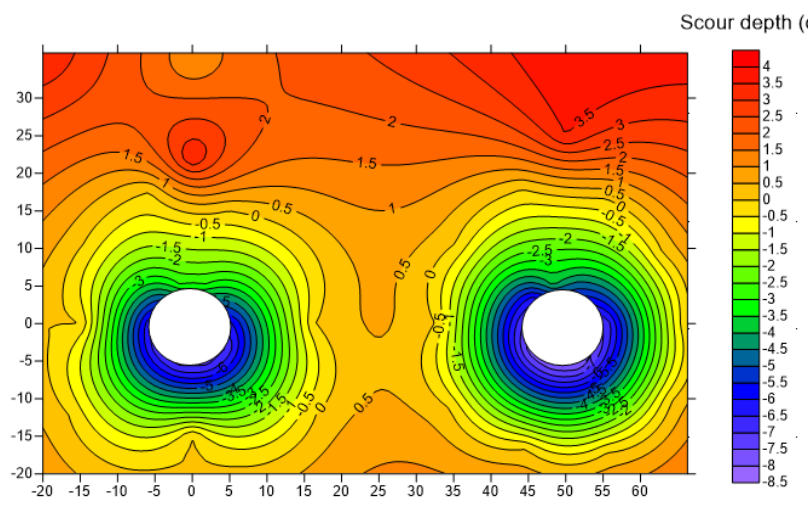

Fig. 4b. Scour morphology and the deposition ridge around the 11 -cm-pier under smooth ice-covered condition for $D_{50}=0.47 \mathrm{~mm}$.

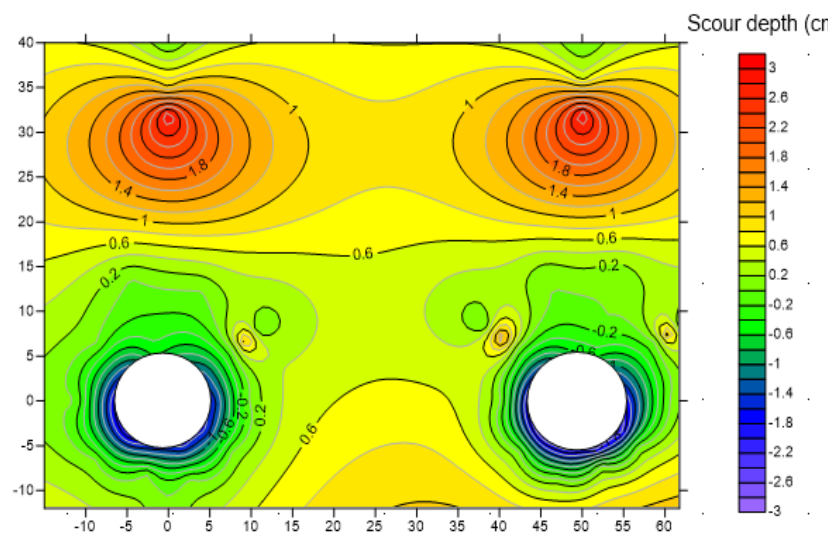

Fig. 4c. Scour morphology and the deposition ridge around the 11 -cm-pier under smooth ice-covered condition for $D_{50}=0.58 \mathrm{~mm}$.

Figure $5 \mathrm{~b}$ shows that, for the same sediment (such as $D_{50}=0.47$ $\mathrm{mm}$ ), the deepest scour hole has occurred under rough ice-covered flow condition. Besides, regardless of flow cover, the maximum scour depth is located at the upstream face, namely, location point 7 for the 9-cm-pier, similar to that of the 11-cm-pier. According to Sui et al. (2010), the existence of an ice cover on water surface doubles the wetted perimeter compared to that under open flow condition, and alters the hydraulics of an open channel by imposing an extra boundary to the flow. As a consequence, the maximum flow velocity is shifted towards the channel bed. The velocity profile is significant changed (comparing to that under open flow condition). Thus, the strength of primary horseshoe vortexes under ice-covered flow condition is amplified, this leads to more intense scour depths. Under covered flow condition, the roughness of ice cover has significant impacts on velocity field and flow characteristics, namely, the rougher the ice cover, the more effects on velocity field and flow characteristics. For channel bed with the

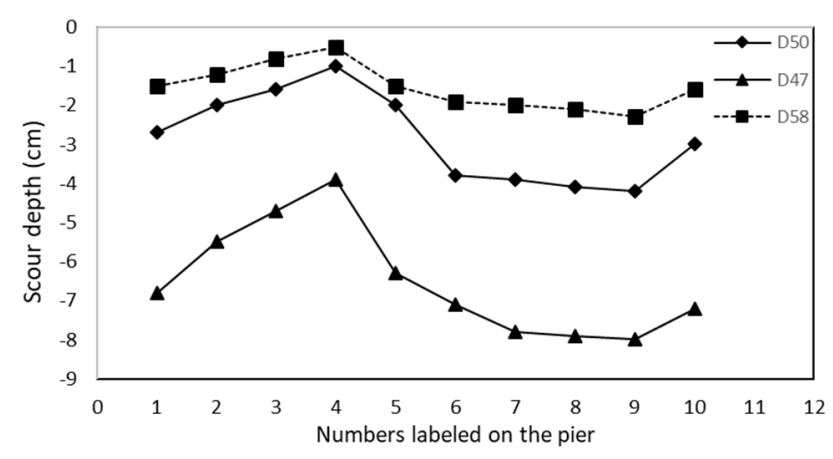

Fig. 5a. Scour profiles around the 11-cm-pier under smooth icecovered flow condition.

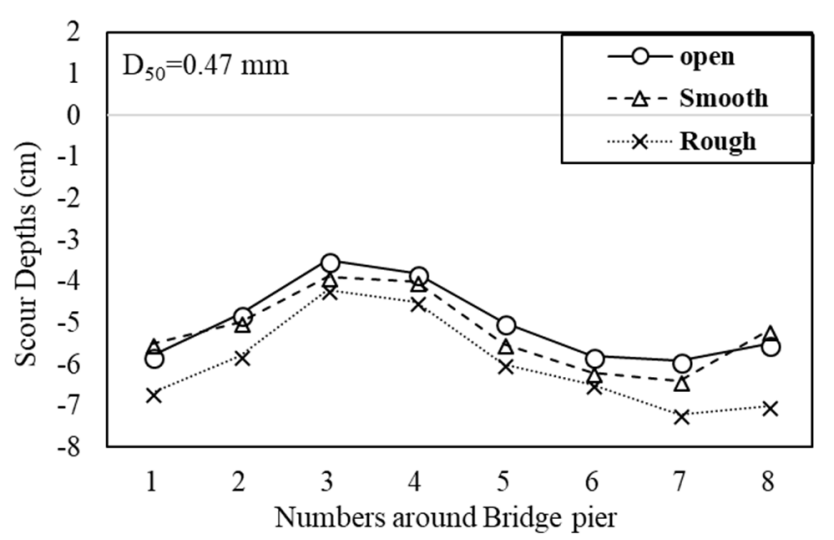

Fig. 5b. Scour profiles around the 9-cm-pier under ice-covered and open channel flow condition for $D_{50}=0.47 \mathrm{~mm}$.

same sediment, the rough ice cover will lead to a deeper scour hole comparing to that of smooth ice-cover.

Figure 6a shows the pattern of scour hole and deposition ridge around the $11-\mathrm{cm}$ pier under rough covered flow condition $\left(D_{50}=\right.$ $0.58 \mathrm{~mm})$, while Figure $6 \mathrm{~b}$ shows scour depths around the $9-\mathrm{cm}-$ pier under different boundary conditions for $D_{50}=0.47 \mathrm{~mm}$. Results indicate that, regardless of the roughness of ice cover and grain size of sediment, the maximum scour depths always occur at the upstream front face of bridge piers. It has been observed from experiments that the horseshoe vortex shifts the maximum downflow velocity closer to the pier in the scour hole. Besides, under covered condition, the strength of this downflow jet is intensified. The eroded sand particles are carried around the pier by the combined action of accelerating flow and the spiral motion of the horseshoe vortex. As clearly showed in Figure 6a, the deposition ridge has been formed downstream of the pier. Melville and Coleman (2000) stated that the wake-vortex system acts like a vacuum cleaner sucking up stream bed material and carrying the sediment moved by the horseshoe vortex system and by the downward flow to the downstream of the pier. However, wake vortices are normally not as strong as the horseshoe vortices and therefore, they are not able to carry the same amount of sediment load as that carried by the horseshoe vortex. Hereby, sediment deposition occurs downstream of bridge piers in the form of deposition mound as shown in Figure 6a.

\section{Scour area and scour volume}

Accurate determination of scour volume and scour area is important in practical decision-making for the control of local scour and safe design of countermeasures. However, there is very limited research work for examining the scour volume and scour area under ice-covered flow condition. Wu et al. (2014) 


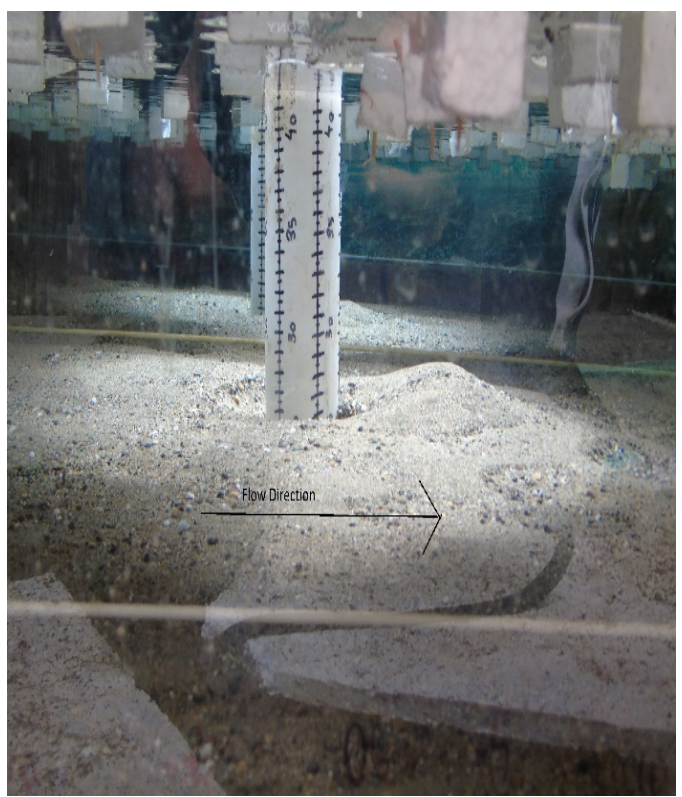

Fig. 6a. a view of the scour pattern and deposition ridge around the $11-\mathrm{cm}$ pier under rough ice-covered condition $\left(D_{50}=0.58\right.$ $\mathrm{mm})$.

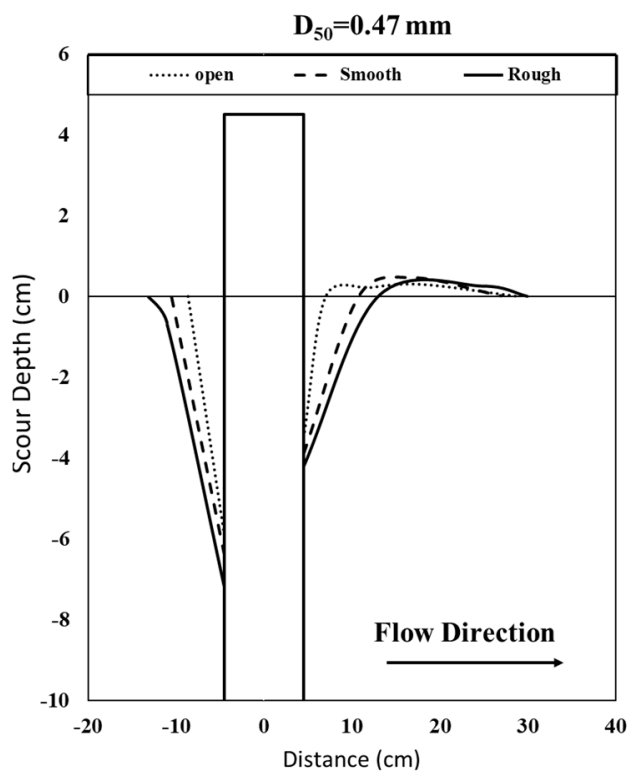

Fig. 6b. Cross sections of scour and deposition ridge around the 9-cm-piers under open channel, smooth and rough covered flow conditions $\left(D_{50}=0.47 \mathrm{~mm}\right)$.

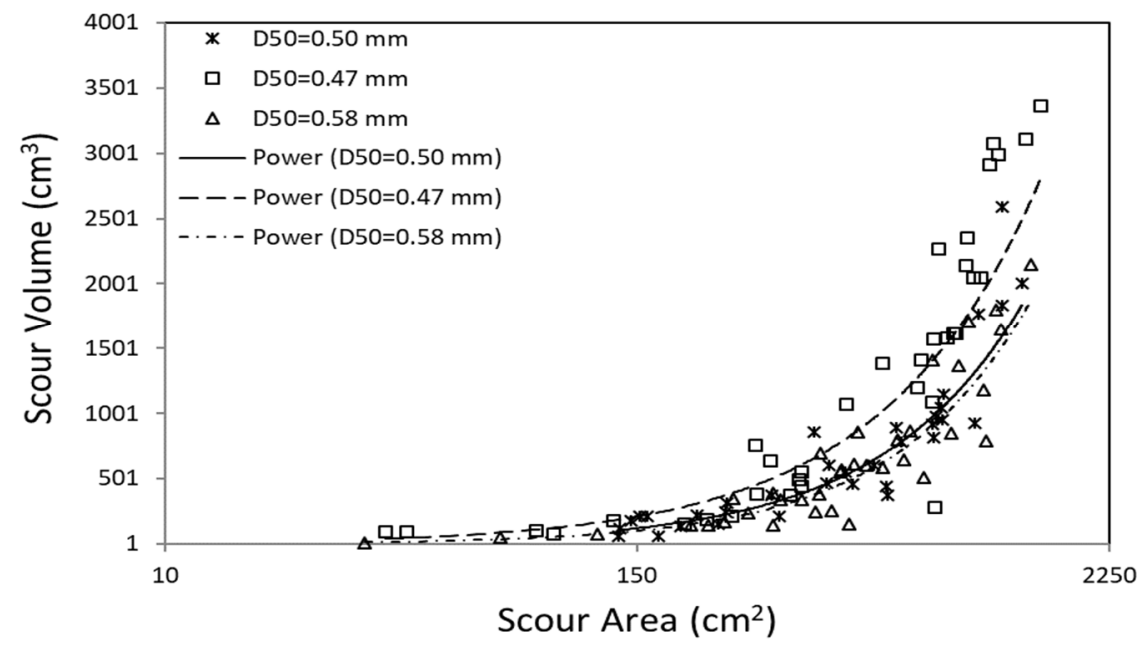

Fig. 7. Relationship between scour volume and scour area.

found that there was a linear correlation between scour depth and volume of scour hole around bridge abutments under ice covered condition. Khwairakpam et al. (2012) developed two formulae to estimate scour volume and scour area around a vertical pier under clear water condition in terms of approach flow depth and pier diameter. Figure 7 gives the relationship between scour volume (V) and scour area (A) in terms of grain size of sediment. These relationships can be described as follows:

Under open flow condition:

$V=0.229 A^{1.256}$

Under ice-covered flow condition:

$V=0.465 A^{1.158}$
In which $V$ is volume of scour hole $\left(\mathrm{cm}^{3}\right)$ and $A$ is surface area of scour hole. The following results are obtained from the scour volume and scour area analysis.

(a) In terms of grain size of sediment, under the same flow condition, the finest sediment $\left(D_{50}=0.47 \mathrm{~mm}\right)$ yielded the largest scour volume and scour area and the impact of ice cover on scour volume and scour area is more significant for finer sediment type. On the other hand, under the same flow conditions, the coarsest sediment (namely, $D_{50}=0.58 \mathrm{~mm}$ ) yielded the smallest scour volume and scour area.

(b) In terms of flow cover, results indicated that the flow under ice-covered condition led to larger amount of scour volume and scour area. It was found that, the maximum amount of scour volume and scour area occurred under rough covered flow condition. Also, under the same flow condition, intense scouring process around bridge piers with smaller pier spacing has been observed, especially in channel bed with the finest sediment. 


\section{Grain size analysis of armour layer}

Sieve analyses (ASTM D422-63) were performed to obtain the grain size distribution of the three non-uniform sediments. The grain size distribution curves for these three non-uniform sediments used in this experimental study are displayed in Figure 8. Sieve analyses revealed that the material collected was almost exclusively coarser than $0.075 \mathrm{~mm}$ (\#200 sieve). The sediments were classified according to the unified soil classification system (ASTM D2487-11). All three sediments were classed as poorly-graded sands (SP).

As the experiments initiated, the armour layer evolution gradually started to develop inside the scour hole. The first sign of armour layer development was inside the scour hole at the upstream face of the pier where the downflow and horseshoe vortex exists and in which the armour layer was denser. The armour layer then extended to the sides and downstream of the pier, where the armour layer particles were more separated from each other and it eventually disintegrates at the end of the deposition ridge. Results showed that the armour layer which was formed on the deposition ridges was composed of finer sediment particles compared to those of armour layer formed inside the scour holes. The maximum depth of scour hole remained quite constant once the armour layer was formed which is due to the slope stability caused by formation of the armour layer. The samples of armour layer developed within the scour hole were collected for each experimental run and the $D_{50}$ of the armour layers were extracted from armour layer grain size distribution graphs (described as $D_{50 \mathrm{~A}}$ ). Figure 9 displays the distribution curves of grain sizes of armour layer in scour hole around the 11-cm-pier for $D_{50}=0.50 \mathrm{~mm}$ compared to those of the original sands and deposition ridge under rough covered flow condition. Table 1 also shows the grain size characteristics of samples of armour layers in scour holes around the $11-\mathrm{cm}-$ pier compared to those of correspondingly deposition ridges for three sands under rough covered flow condition. One can see from Table 1, the armour layer generated in sand bed of $D_{50}=$ $0.58 \mathrm{~mm}$ is coarser than that in sand beds of $D_{50}=0.47 \mathrm{~mm}$ and $D_{50}=0.50 \mathrm{~mm}$. To better distinguish the difference in grain size distributions between the samples of armour layers in scour holes and the samples of the associate deposition ridges, the grain size distributions are separately displayed in Figures $10(\mathrm{a}-\mathrm{b})$. Results indicate that the armour layer generated in sand bed of $D_{50}=0.58 \mathrm{~mm}$ is the coarsest comparing to those of $D_{50}=0.47 \mathrm{~mm}$ and $D_{50}=0.50 \mathrm{~mm}$. Regarding the deposition ridge in sand bed of $D_{50}=0.58 \mathrm{~mm}$, the deposition ridge is covered by coarsest sand particles comparing to those of $D_{50}=$ $0.47 \mathrm{~mm}$ and $D_{50}=0.50 \mathrm{~mm}$. With decrease in $D_{50}$ of the original sand, the grain size of the armour layer decreases correspondingly. These results are in good agreement with findings of Wu et al (2015) who investigated the armour layer in scour holes around square and semi-circular abutments.

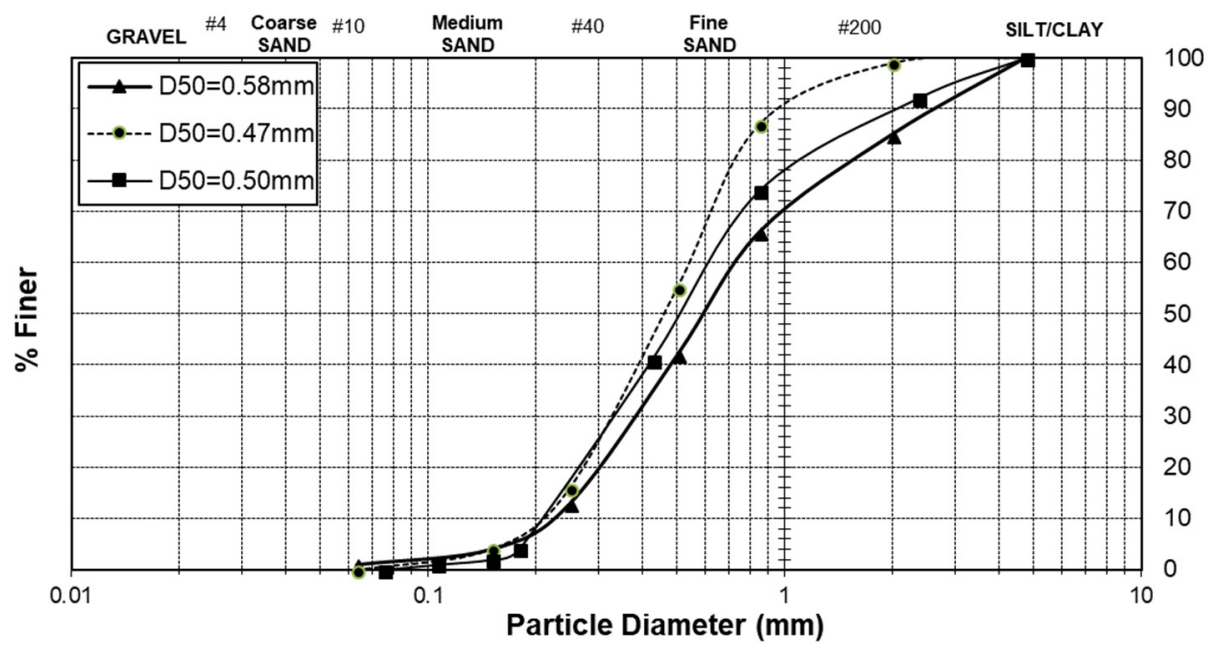

Fig. 8. Grain size distribution curves of three non-uniform sands used in this study.

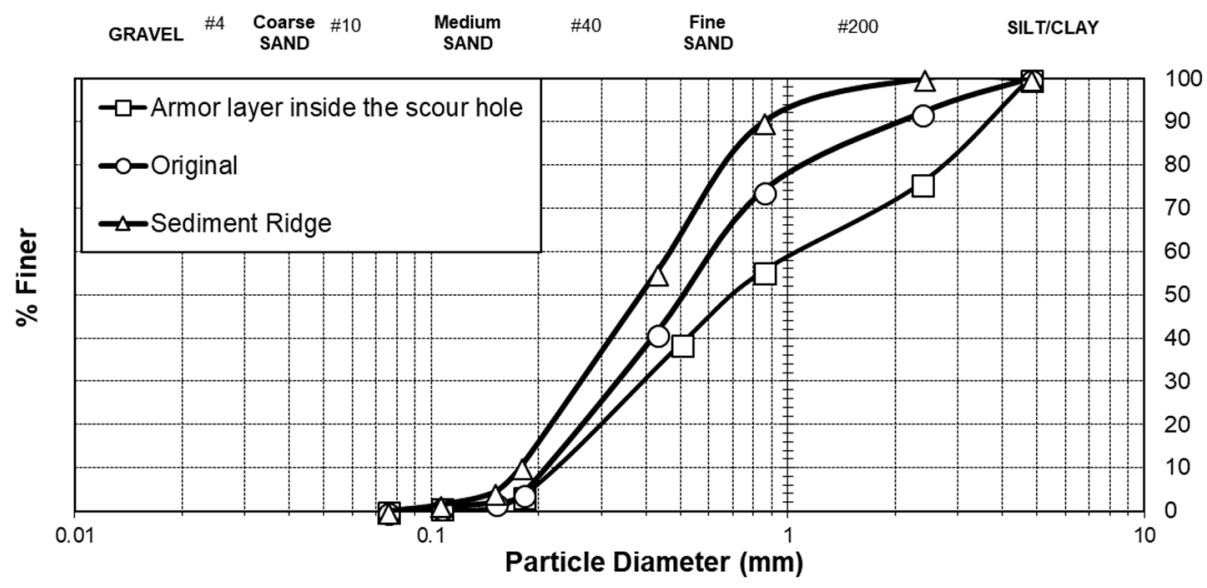

Fig. 9. Grain size distribution curves of the armour layer in scour hole around the 11-cm-pier, original sand and deposition ridge for sand bed of $D_{50}=0.50 \mathrm{~mm}$ under rough covered condition. 


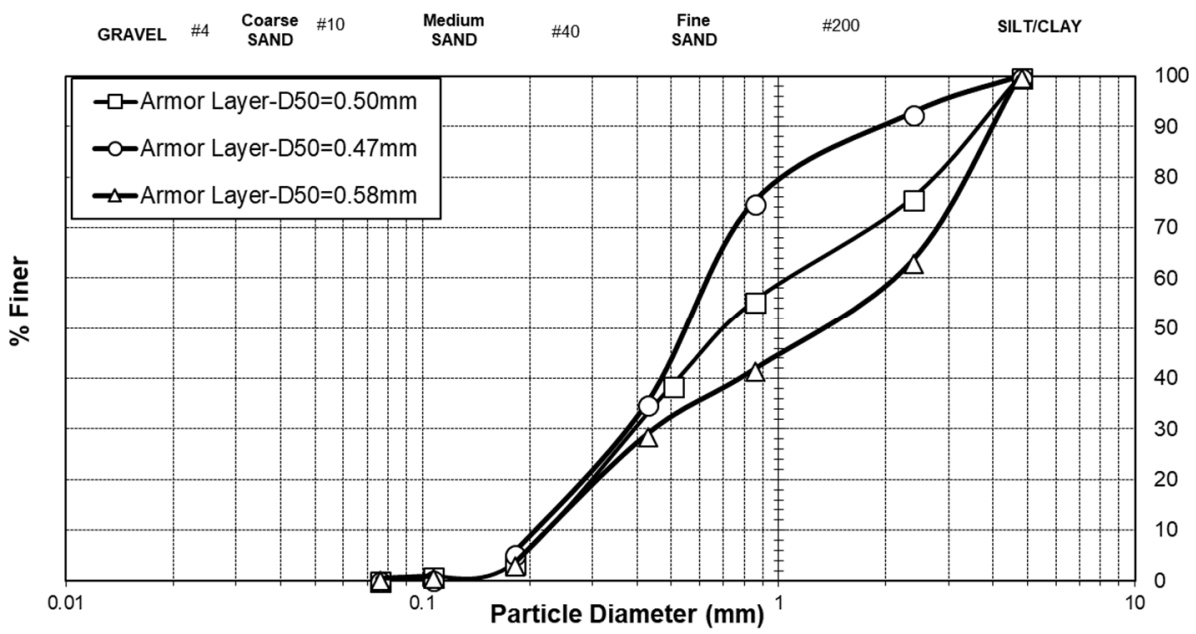

Fig. 10a. Grain size distributions of armour layer samples in scour hole generated from three sands around the 11-cm-pier.

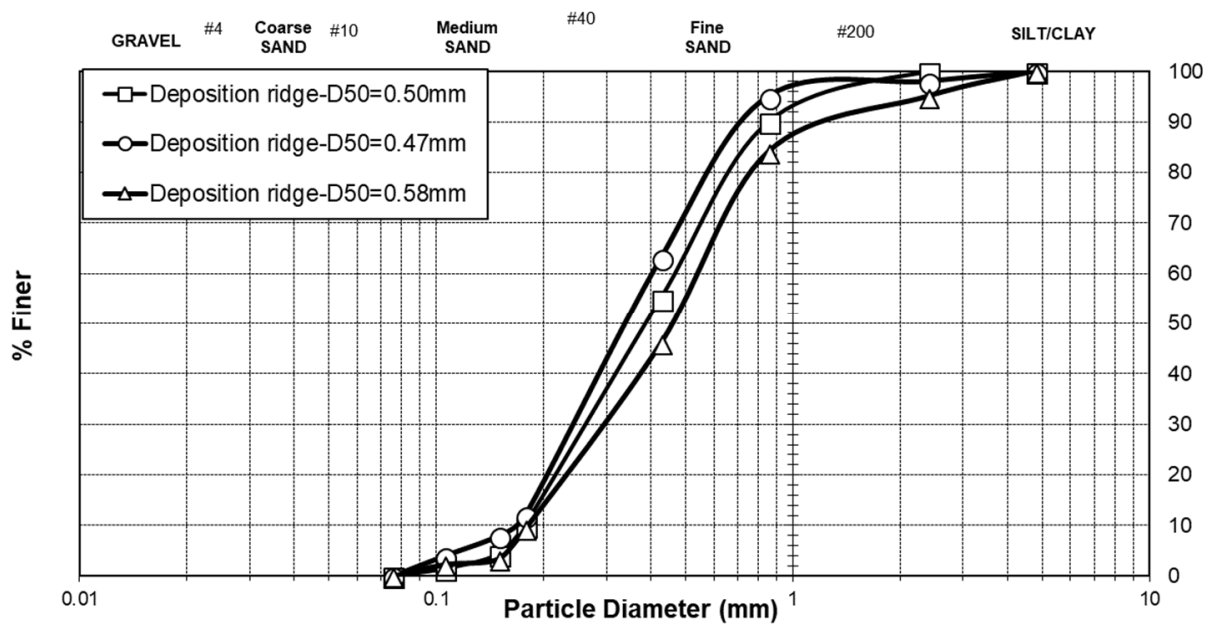

Fig. 10b. Grain size distributions of samples of deposition ridge generated from three sands downstream of the 11-cm-pier.

Table 1. Grain size characteristics of samples of armour layer in scour hole around the 11-cm-pier under rough covered flow condition compared to those of associated deposition ridge.

\begin{tabular}{lcccccccccc}
\hline & $\begin{array}{c}D_{10} \\
(\mathrm{~mm})\end{array}$ & $\begin{array}{c}D_{16} \\
(\mathrm{~mm})\end{array}$ & $\begin{array}{c}D_{30} \\
(\mathrm{~mm})\end{array}$ & $\begin{array}{c}D_{50} \\
(\mathrm{~mm})\end{array}$ & $\begin{array}{c}D_{60} \\
(\mathrm{~mm})\end{array}$ & $\begin{array}{c}D_{84} \\
(\mathrm{~mm})\end{array}$ & $\begin{array}{c}D_{90} \\
(\mathrm{~mm})\end{array}$ & $\begin{array}{c}\text { Geometric } \\
\text { standard } \\
\text { deviation } \\
\left(\sigma_{g}\right)\end{array}$ & $\begin{array}{c}\text { Uniformity } \\
\text { coefficient } \\
\left(C_{U}\right)\end{array}$ & $\begin{array}{c}\text { Coefficient of } \\
\text { curvature }\left(C_{c}\right)\end{array}$ \\
\hline $\begin{array}{l}\text { Sample 1, for } \\
D_{50}=0.50 \mathrm{~mm}\end{array}$ & 0.22 & 0.28 & 0.40 & 0.70 & 1.10 & 3.30 & 3.80 & 3.43 & 5.00 & 0.66 \\
\hline $\begin{array}{l}\text { Sample 2, for } \\
D_{50}=0.47 \mathrm{~mm}\end{array}$ & 0.21 & 0.26 & 0.38 & 0.55 & 0.62 & 1.40 & 2.10 & 2.32 & 2.95 & 1.11 \\
\hline $\begin{array}{l}\text { Sample 3, for } \\
D_{50}=0.58 \mathrm{~mm}\end{array}$ & 0.23 & 0.28 & 0.39 & 1.40 & 2.10 & 3.80 & 4.00 & 3.68 & 9.13 & 0.31 \\
\hline $\begin{array}{l}\text { Sample 1, for } \\
D_{50}=0.50 \mathrm{~mm}\end{array}$ & 0.18 & 0.21 & 0.27 & 0.40 & 0.48 & 0.75 & 0.88 & 1.89 & 2.67 & 0.84 \\
\hline $\begin{array}{l}\text { Sample 2, for } \\
D_{50}=0.47 \mathrm{~mm}\end{array}$ & 0.17 & 0.19 & 0.24 & 0.34 & 0.40 & 0.63 & 0.72 & 1.82 & 2.35 & 0.85 \\
\hline $\begin{array}{l}\text { Sample 3, for } \\
D_{50}=0.58 \mathrm{~mm}\end{array}$ & 0.18 & 0.21 & 0.30 & 0.47 & 0.53 & 0.90 & 1.30 & 2.07 & 2.94 & 0.94 \\
\hline
\end{tabular}

\section{Determination of scour depth with influence of armour layer}

Considering a bridge pier in a river whose flow is assumed to be steady and uniform, Breusers et al. (1977) pointed out that following parameters may influence the scouring phenomenon as follows: 1) variables characterizing the fluid such as acceleration due to gravity $(\mathrm{g})$ and density of fluid $\left(\rho_{w}\right) ; 2$ ) variables characterizing the bed material such as sediment density $\left(\rho_{s}\right)$, median grain size of the bed material $\left(D_{50 B}\right)$ and median grain 
size of sediment particles of the armor layer; 3) variables characterizing the flow such as depth of approaching flow $\left(y_{0}\right)$ and the mean velocity of approaching flow $(U) ; 4)$ variables characterizing the bridge pier and channel geometry such as pier shape and size and channel width. In addition to abovementioned parameters, in the present study, the effect of ice cover roughness is an important parameter which must be considered. Therefore, conceptually at least, with influence of armour layer in scour hole around bridge pier, the maximum scour depth of scour hole may be evaluated by means of a general formula for computation:

$$
y_{\max }=f\left(U, g, D_{50 A}, D_{50 B}, n_{b}, n_{i}, D, B, y_{0}, \rho_{w}, \rho_{s}\right)
$$

In which, $y_{\max }$ is the maximum depth of scour hole around bridge pier; $D_{50 A}$ is the median grain size of armour layer; $n_{b}$ is the Manning roughness coefficient of channel bed; $n_{i}$ is Manning roughness coefficient of ice cover; $D$ is the diameter of bridge pier; $B$ is the channel width; $\rho_{w}$ and $\rho_{s}$ are the density of water and sediment, respectively, with $\Delta \rho=\rho_{s}-\rho_{w}$. Through dimensional analysis by means of Buckingham $\pi$ theories, the maximum depth of scour hole can be expressed as follows

$$
\frac{y_{\max }}{D_{50 A}}=f\left(\frac{U}{\sqrt{\left(\Delta \rho / \rho_{W}\right) g D_{50 A}}}, \frac{D_{50 A}}{D_{50 B}}, \frac{n_{i}}{n_{b}}, \frac{D_{50 A}}{y_{0}}, \frac{D_{50 A}}{B}, \frac{D_{50 A}}{D}\right)
$$

$$
\text { The term } F r_{0}=\frac{U}{\sqrt{\left(\Delta \rho / \rho_{W}\right) g D_{50 A}}} \text { is called densimetric }
$$

Froude number and is a criterion of hydraulic conditions for assessment of the incipient motion of bed material (Aguirre-Pe et al., 2003). It is a term that describes the incipient motion of the sediment articles. The larger the densiometric Froude number, the larger shear stress is needed to transport the sediment particles. Eq. (4) can be also expressed as follows:

$$
\frac{y_{\max }}{D_{50 A}}=A\left(F r_{0}\right)^{a}\left(\frac{D_{50 A}}{D_{50 B}}\right)^{b}\left(\frac{n_{i}}{n_{b}}\right)^{c}\left(\frac{D_{50 A}}{y_{0}}\right)^{d}\left(\frac{D_{50 A}}{B}\right)^{e}\left(\frac{D_{50 A}}{D}\right)^{f}
$$

Since the value of $D_{50 A} / B$ is truly tiny, the term $D_{50 A} / B$ can be neglected from Eq. (5). Besides, the term $\left(D_{50 A} / y_{0}\right)$ can be also ignored from Eq. (5) due to its weak correlation with $\left(y_{\max } / D_{50 A}\right)$. Therefore, the following parameters have been used to assess the relative maximum scour depth (MSD) of scour hole $\left(y_{\max } / D_{504}\right)$ around bridge pier.

$$
\frac{y_{\max }}{D_{50 A}}=A\left(\frac{D_{50 A}}{D_{50 B}}\right)^{a}\left(\frac{D_{50 A}}{D}\right)^{b}\left(\frac{n_{i}}{n_{b}}\right)^{c}\left(F r_{0}\right)^{d}
$$

In the case of open channel flow condition, the ratio of roughness coefficient of ice cover to roughness coefficient of channel bed would be omitted from Eq. (6). Each of the independent dimensionless variables of Eq. (6) were assessed separately to study their impact on the local scour around bridge piers.

\section{a) Variation of relative MSD $\left(y_{\max } / D_{50 A}\right)$ with densimetric Froude number (Fro)}

Figure 11 illustrates the variation of relative MSD with densimetric Froude number $\left(F r_{0}\right)$. With increase in $F r_{0}$, the relative MSD increases correspondingly. Besides, under the same $\mathrm{Fr}_{0}$, the values of the relative MSD under ice-covered conditions are larger than those under open flow condition. On the other hand, with the same values of relative MSD, the larger value of densimetric Froude number is needed to initiate sediment transportation for the open channel flow condition which means that a lower values of shear stress is needed to initiate motion for sediment transportation under ice-covered flow conditions.

\section{b) Variation of relative MSD $\left(y_{\max } / D_{504}\right)$ with the grain size of armour layer $\left(D_{50 A} / D_{50 B}\right)$}

Figure 12a illustrates the variation of relative MSD $\left(y_{\max } / D_{50 A}\right)$ against ratio of grain size of armour layer $\left(D_{50 A} / D_{50 B}\right)$ distinguished by different pier sizes. Regardless of size of bridge pier, as the grain size of armour layer $\left(D_{50 A} / D_{50 B}\right)$ increases, the relative MSD of scour hole decreases and vice versa. From Figure 12b, one can see that the variation of relative MSD $\left(y_{\max } / D_{50 A}\right)$ against ratio of $\left(D_{50 A} / D_{50 B}\right)$ distinguished by different covered conditions. Regardless of flow cover, the relative MSD ( $\left.y_{\max } / D_{50 A}\right)$ decreases as the grain size of armour layer $\left(D_{50 A} / D_{50 B}\right)$ increases. Under rough covered condition, the relative MSD $\left(y_{\max } / D_{50 A}\right)$ showed a sharper descending trend with the grain size of armour layer $\left(D_{50 A} / D_{50 B}\right)$ compared to those of under both smooth covered and open flow conditions. Also, under smooth covered flow condition, the relative MSD $\left(y_{\max } / D_{50 A}\right)$ showed a sharper descending trend with the grain size of armour layer $\left(D_{50 A} / D_{50 B}\right)$ compared to those of under open flow condition. The reason for this is due to strong turbulent flows and different velocity fields close to channel bed which are caused by ice cover, and it get more intensified under rough covered flow condition. Similar results were also reported by Dey and Raikar (2007).

\section{c) Variation of relative MSD $\left(y_{\max } / D_{50 A}\right)$ with the pier spacing (D50A/D)}

Figure 13 illustrates the variation of relative MSD $\left(y_{\max } / D_{50 A}\right)$ with ratio of the pier spacing $\left(D_{50 A} / D\right)$ distinguished by different covered conditions. Regardless of flow cover, the relative MSD $\left(y_{\max } / D_{50 A}\right)$ decreases with increase in ratio of the pier spacing $\left(D_{50 A} / D\right)$. Under rough covered condition, the relative MSD $\left(y_{\max } / D_{50 A}\right)$ showed a sharper descending trend with the pier spacing $\left(D_{504} / D\right)$ compared to those of under both smooth covered and open flow conditions. Besides, under the same values of $\left(D_{50 A} / D\right)$, the rough ice-covered flow has resulted in largest relative MSD.

\section{d) Variation of relative $M S D\left(y_{\max } / D_{504}\right)$ with roughness of ice cover $\left(n_{i} / n_{b}\right)$}

As pointed out by Mays (1999), due to a relatively smooth concrete-like surface of the Styrofoam panel, the roughness of the model smooth ice-cover was assumed to be 0.013 . In terms of model rough ice-cover, Li (2012) reviewed several methods for calculating the Manning's coefficient for ice cover, the following equation can be used depending on the size of the small cubes:

$$
\frac{n_{i}}{k_{S}^{1 / 6}}=\frac{(8 g)^{-1 / 2}\left(R / K_{S}\right)^{1 / 6}}{0.867 \ln \left(12 R / K_{S}\right)}
$$

In which, $K_{s}$ is the average roughness height of the ice cover underside and $\mathrm{R}$ is the hydraulic radius. By using Eq. (7), a Manning's coefficient of 0.021 was determined as the roughness coefficient of model rough ice cover. This value also agrees with result of Hains et al. (2004). To calculate channel bed roughness coefficient for non-uniform sand bed, the following equation proposed by Hager (1999) was used: 


$$
n_{b}=0.039 D_{50}^{1 / 6}
$$

Therefore, the roughness coefficient of sand bed $n_{b}$ is determined as 0.0109 for sand bed of $D_{50}=0.47 \mathrm{~mm}, 0.0110$ for sand bed of $D_{50}=0.050 \mathrm{~mm}$, and 0.0113 for sand bed of $\mathrm{D}_{50}=$ $0.58 \mathrm{~mm}$, respectively. Results indicate that with increase in $n_{i} / n_{b}$, the relative MSD $\left(y_{\max } / D_{50 A}\right)$ increases correspondingly. Following Equations (9) and (10) are developed to predict the relative MSD $\left(y_{\max } / D_{50 A}\right)$ under ice-covered condition and open flow condition, respectively.

Open flow condition:

$\frac{y_{\max }}{D_{50 A}}=1.433\left(F r_{0}\right)^{1.289}\left(\frac{D_{50 A}}{D_{50 B}}\right)^{-0.190}\left(\frac{D_{50 A}}{D}\right)^{-0.488} R^{2}=0.85$

Ice-covered flow condition:

$\frac{y_{\max }}{D_{50 A}}=47.190\left(F r_{0}\right)^{0.892}\left(\frac{D_{50 A}}{D_{50 B}}\right)^{-0.652}\left(\frac{D_{50 A}}{D}\right)^{-0.367}\left(\frac{n_{i}}{n_{b}}\right)^{0.484}$

$R^{2}=0.88$
According to Equation (9) and Equation (10), the most significant variable is the densimetric Froude number since this variable has the largest power comparing to all other variables. Figure 14 showed the comparison of calculated relative MSD $\left(y_{\max } / D_{50 A}\right)$ to those observed under open flow condition, and Figure 15 show the comparison of calculated relative MSD $\left(y_{\max } / D_{50 A}\right)$ to those observed under ice-covered flow condition. As showed in Figures 14 and 15, the calculated relative MSD $\left(y_{\max } / D_{50 A}\right)$ agreed well with those observed under both open flow condition and ice-covered condition.

To better specify the correlation of different dimensionless variables of Equation (10) with each other and their impact on the relative MSD $\left(y_{\max } / D_{504}\right)$, different combination of those dimensionless variables are generated in Table 2. As one can see from Table 2 the densimetric Froude number is the most dominant parameter since its individual $R^{2}$ coefficient is 0.784 . The next dominant term is ratio of grain size of armour layer $\left(D_{50 A} / D_{50 B}\right)$ with $R^{2}$ coefficient of 0.694 . With respect to combination of two terms, the combination of $\left(D_{504} / D_{50 B}\right)$ and $\left(F r_{0}\right)$ is the most accurate one with $R^{2}$ equal to 0.787 . With respect to combination of three terms, the combination of $\left(n_{i} / n_{b}\right)$; $\left(D_{50 A} / D\right) ;\left(F r_{0}\right)$ is the most accurate with $R^{2}$ equal to 0.857 .

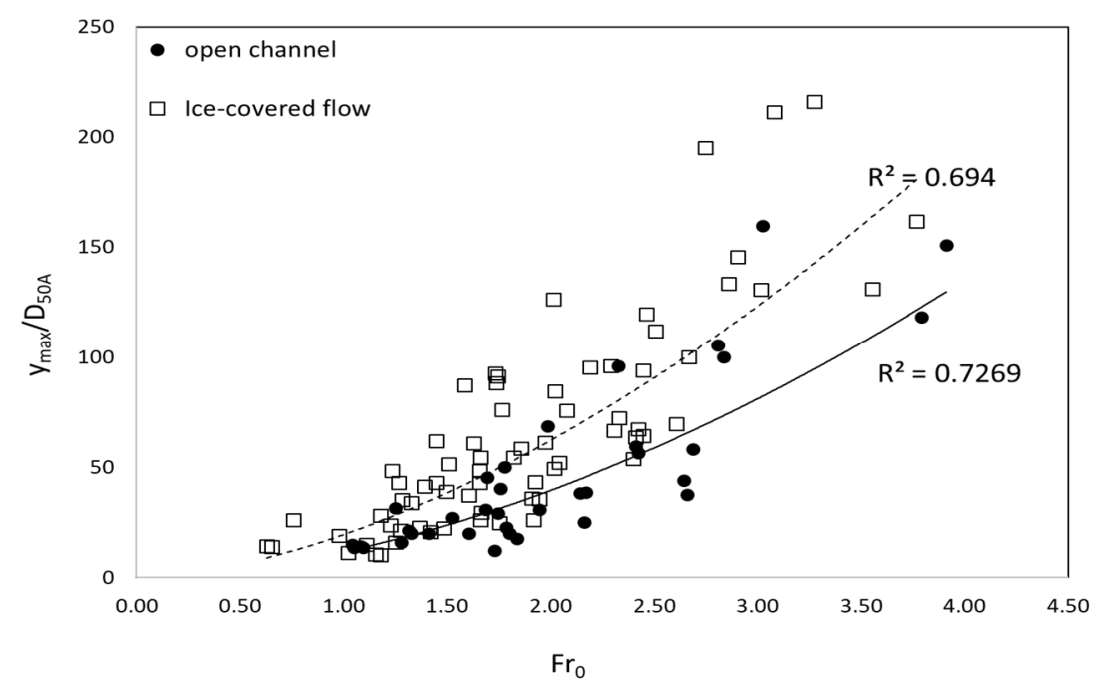

Fig. 11. Relation between the relative MSD $\left(y_{\max } / D_{50 A}\right)$ with densimetric Froude number $\left(F r_{0}\right)$.

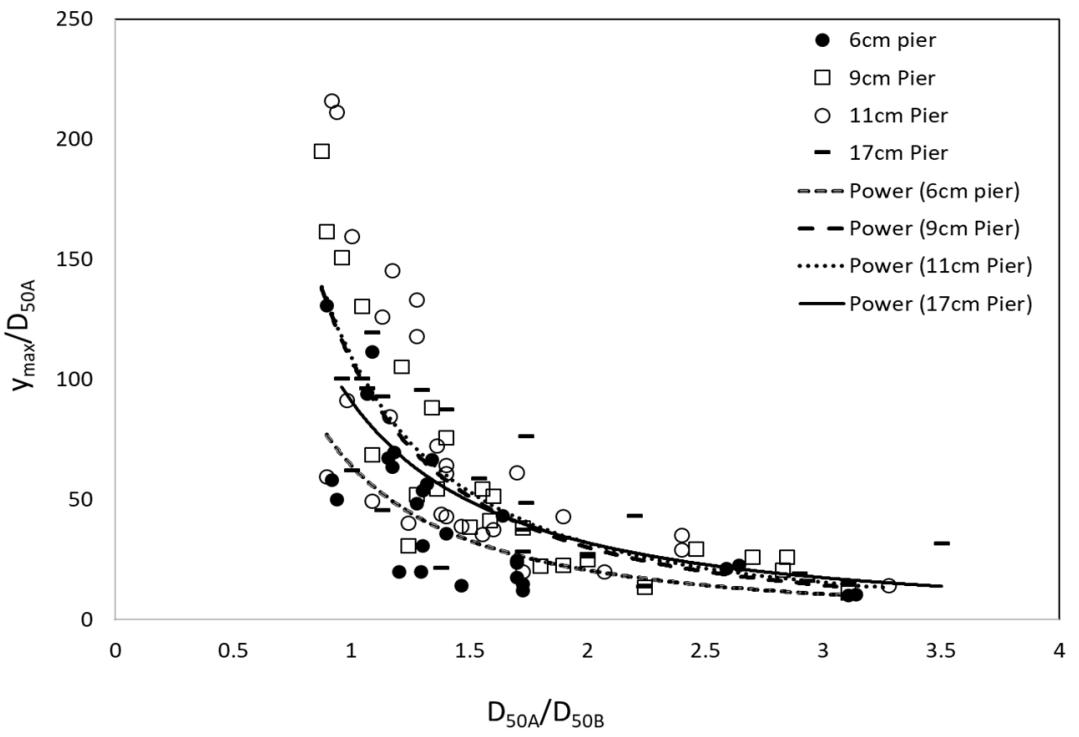

Fig. 12a. Variation of relative MSD $\left(y_{\max } / D_{50 A}\right)$ with $\left(D_{50 A} / D_{50 B}\right)$ distinguished by pier size. 


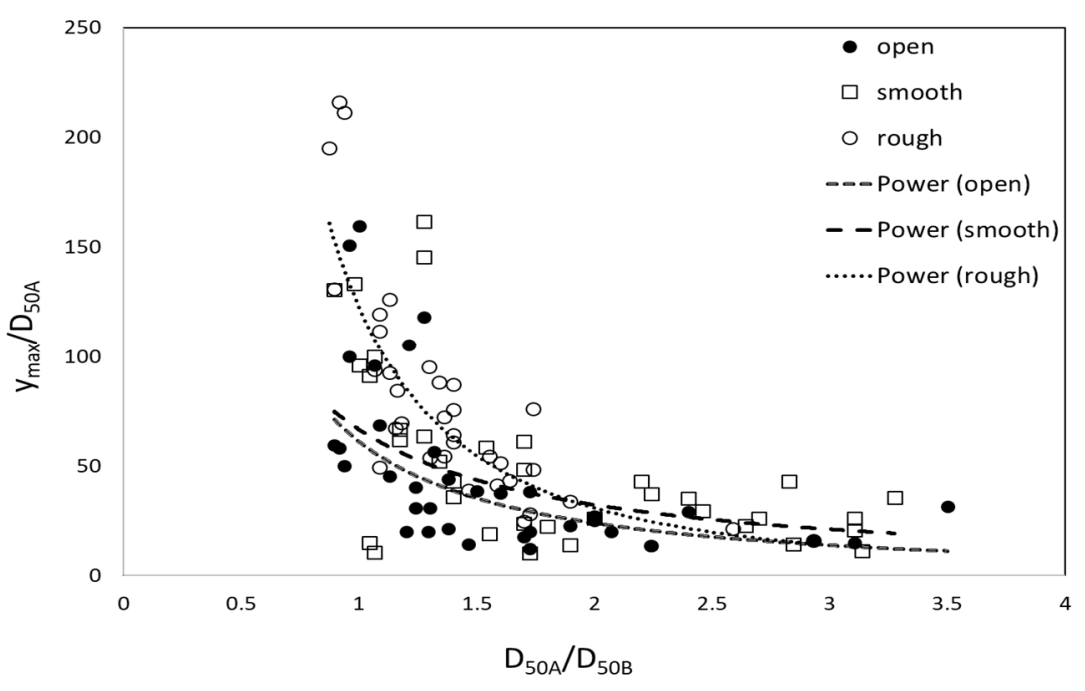

Fig. 12b. Variation of relative MSD $\left(y_{\max } / D_{50 A}\right)$ with $\left(D_{50 A} / D_{50 B}\right)$ distinguished by different covered conditions.

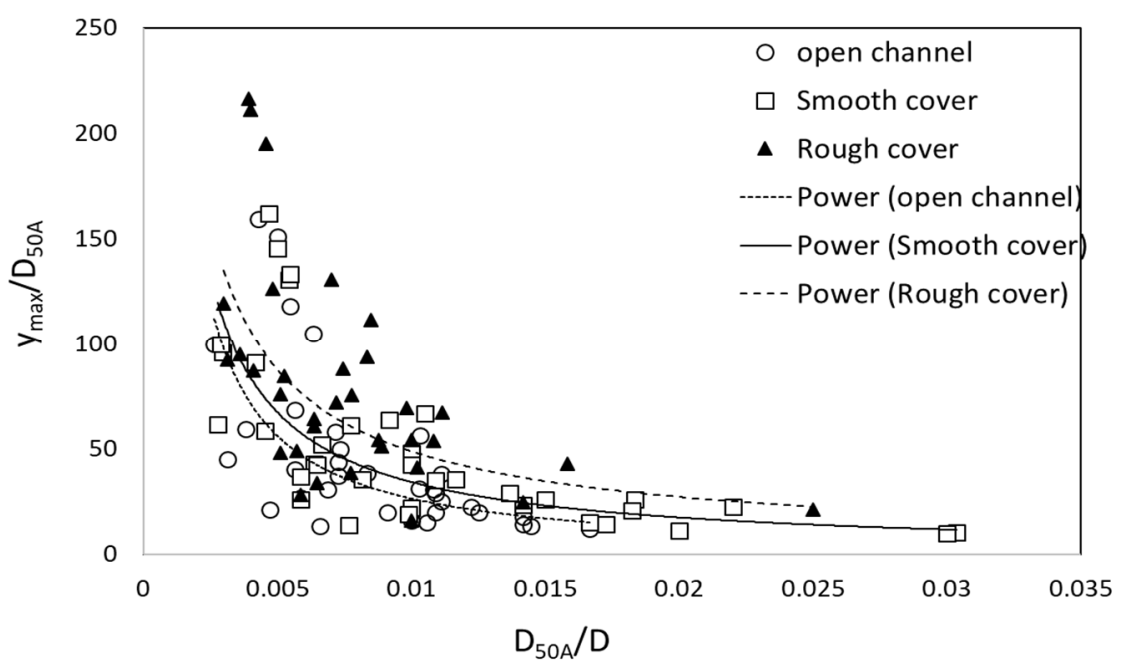

Fig. 13. Variation of relative MSD $\left(y_{\max } / D_{50 A}\right)$ with the ratio of pier spacing $\left(D_{50 A} / D\right)$ distinguished by different covered conditions.

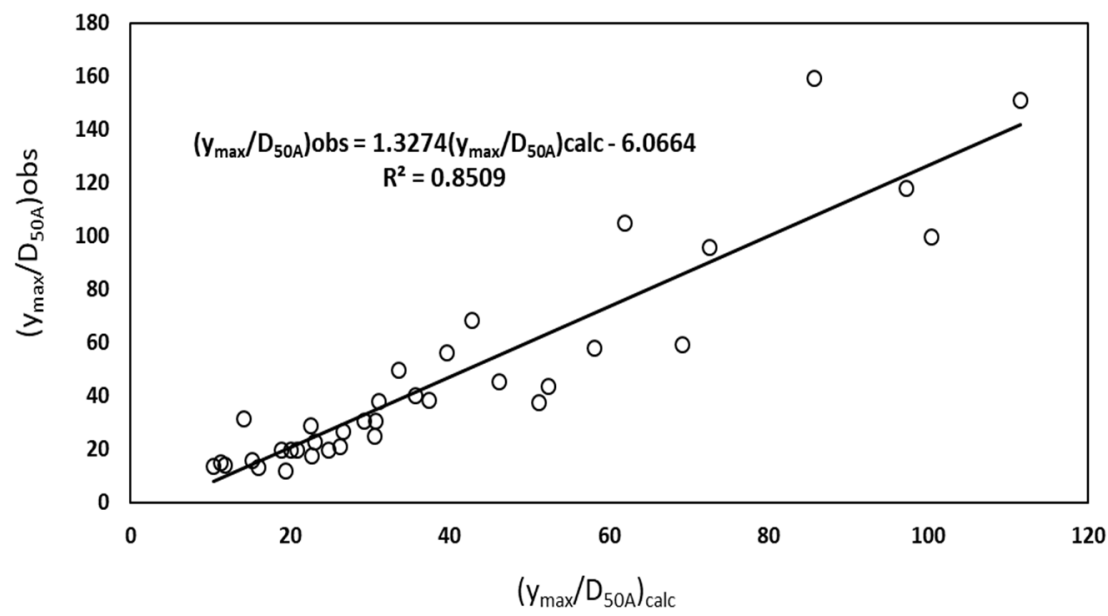

Fig. 14. Comparison of calculated relative $\operatorname{MSD}\left(y_{\max } / D_{50 A}\right)$ to those observed under open flow condition. 


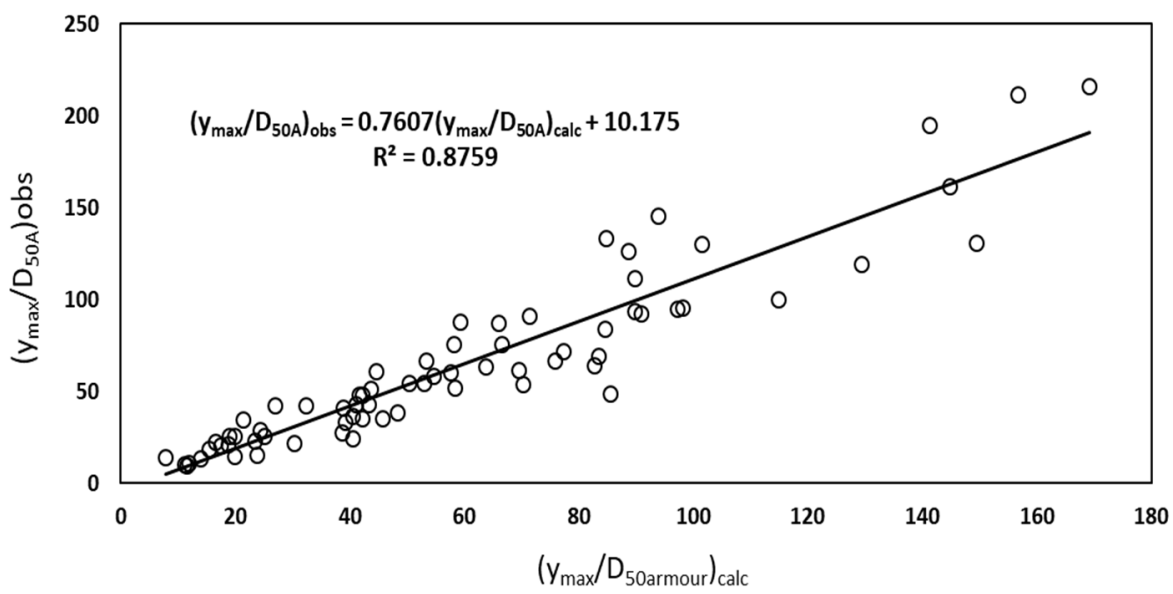

Fig. 15. Comparison of calculated relative $\operatorname{MSD}\left(y_{\max } / D_{50 A}\right)$ to those observed under ice-covered flow condition.

Table 2. Different combinations of dimensionless variables.

\begin{tabular}{lll}
\hline$y_{\max } / D_{50 A} f()$ & \multicolumn{1}{c}{$R^{2}$} & Equation \\
\hline$\left(D_{50 \mathrm{~A}} / D_{50 B}\right) ;\left(n_{i} / n_{b}\right) ;\left(D_{50 A} / D\right) ;\left(F r_{0}\right)$ & 0.890 & $47.190\left(D_{50 A} / D_{50 B}\right)^{-0.652}\left(n_{i} / n_{b}\right)^{0.484}\left(D_{50 A} / D\right)^{-0.367}\left(F r_{0}\right)^{0.892}$ \\
$\left(n_{i} / n_{b}\right) ;\left(D_{50 A} / D\right) ;\left(F r_{0}\right)$ & 0.857 & $21.573\left(n_{i} / n_{b}\right)^{0.613}\left(D_{50 A} / \mathrm{D}\right)^{-0.555}\left(F r_{0}\right)^{1.13}$ \\
$\left(D_{50 A} / D_{50 B}\right) ;\left(D_{50 A} / D\right) ;\left(F r_{0}\right)$ & 0.856 & $7.948\left(D_{50 A} / D_{50 B}\right)^{-0.772}\left(D_{50 A} / D\right)^{-0.32}\left(F r_{0}\right)^{0.889}$ \\
$\left(D_{50 A} / D_{50 B}\right) ;\left(n_{i} / n_{b}\right) ;\left(F r_{0}\right)$ & 0.806 & $47.215\left(D_{50 A} / D_{50 B}\right)^{-1.132}\left(n_{i} / n_{b}\right)^{0.008}\left(F r_{0}\right)^{0.859}$ \\
$\left(D_{50 A} / D_{50 B}\right) ;\left(F r_{0}\right)$ & 0.787 & $45.658\left(D_{50 A} / D_{50 B}\right)^{-1.132}\left(F r_{0}\right)^{0.859}$ \\
$\left(D_{50 A} / D_{50 B}\right) ;\left(n_{i} / n_{b}\right) ;\left(D_{50 A} / D\right)$ & 0.756 & $7.948\left(D_{50 A} / D_{50 B}\right)^{-1.329}\left(n_{i} / n_{b}\right)^{0.313}\left(D_{50 A} / D\right)^{-0.370}$ \\
$\left(D_{50 A} / D_{50 B}\right) ;\left(D_{50} / D\right)$ & 0.748 & $26.245\left(D_{50 A} / D_{50 B}\right)^{-1.577}\left(D_{50 A} / D\right)^{-0.252}$ \\
$\left(D_{50 A} / D_{50 B}\right) ;\left(n_{i} / n_{b}\right)$ & 0.742 & $841.012\left(D_{50 A} / D_{50 B}\right)^{-1.776}\left(n_{i} / n_{b}\right)^{0.533}$ \\
$\left(F r_{0}\right)$ & 0.784 & $19.345\left(F r_{0}\right)^{1.6851}$ \\
$\left(D_{50 A} / D_{50 B}\right)$ & 0.694 & $110.9\left(D_{50 A} / D_{50 B}\right)^{-1.83}$ \\
$\left(D_{50} / D\right)$ & 0.568 & $0.4123\left(D_{50 A} / D\right)^{-0.992}$ \\
$\left(n_{i} / n_{b}\right)$ & 0.137 & $5617.1\left(n_{i} / n_{b}\right)^{1.1492}$ \\
\hline
\end{tabular}

\section{CONCLUSIONS}

In present study, to investigate the impact of armour layer and ice cover on scour depth around bridge piers, three nonuniform sediments and four pairs of model piers were used to conduct 108 experiments in a large-scale flume under both open flow condition and ice-covered flow condition. Following conclusions can be drawn from the present study.

1) Although the scour depth under ice-covered flow condition was larger comparing to that under open flow condition, the geometry of the scour holes under open flow condition is similar to that under ice-covered flow condition. Results showed that, regardless of flow cover, the maximum scour depth decreases with increase in the grain size of armour layer. Also, although the maximum depth of scour hole around largest pier was deepest, the grain size distribution of armor layer in scour hole around larger piers did not show a significant difference from those around smaller piers.

2) Under the same flow condition and same covered condition, the maximum scour depth occurs in channel bed with the finest sediment. Due to the horseshoe vortex system, maximum scour depth is located at the upstream face of the piers and extends along the sides of the piers towards the rear side of the pier where wake vortex exists. Due to effect of ice cover, the horseshoe vortex shifts the maximum downflow velocity closer to the pier in the scour hole. Thus, the strength of down- flow gets more intensified which lead to a larger and wider deposition ridge downstream of the pier.

3) Under the same flow condition, both scour volume and scour area of scour hole in the finest sand bed are largest comparing to those in channel bed with coarser sands. With respect to the impact of ice cover, it was found that both scour volume and scour area of scour hole under rough covered flow condition are largest comparing to those under both smooth covered condition and open flow condition.

4) Based on data collected in laboratory, two formulae have been developed to predict the relative MSD $\left(y_{\max } / D_{50 A}\right)$ under both open flow condition and ice-covered condition. Following dimensionless variables are considered in the proposed formulae for determining the relative MSD $\left(y_{\max } / D_{504}\right)$ : densimetric Froude number $\left(F r_{0}\right)$, grain size of armour layer $\left(D_{50 A} / D_{50 B}\right)$, pier spacing $\left(D_{50 A} / D\right)$, and roughness of ice cover $\left(n_{i} / n_{b}\right)$. Results showed that the calculated relative MSD $\left(y_{\max } / D_{50 A}\right)$ agreed well with those observed under both open flow condition and ice-covered condition.

5) Results showed with increase in densimetric Froude number $\left(F r_{0}\right)$, the relative MSD increases correspondingly. Besides, under the same Fro, the values of the relative MSD under ice-covered conditions are larger than those under open flow condition. Results also indicate that, under ice-covered flow condition, a smaller value of densimetric Froude number is needed to initiate movement of sediment comparing to that 
under open flow condition which can be justified by the higher flow velocity near channel bed under ice-covered flow conditions and its impact on the threshold of sediment motion.

\section{REFERENCES}

Aguirre-Pe, J., Olivero, M.L., Moncada, A.T., 2003. Particle densimetric Froude number for estimating sediment transport. Journal Hydraul. Eng., 129, 6, 428-437.

Breusers, H.N.C., Nicollet, G., Shen, H.W., 1977. Local scour around cylindrical piers. Journal of Hydraulic Research, 15, 3, 211-252.

Bunte, K., Abt, S.R., 2001. Sampling surface and subsurface particle-size distributions in wadable gravel-and cobble-bed streams for analyses in sediment transport, hydraulics, and streambed monitoring. Gen. Tech. Rep. RMRS-GTR-74. US Department of Agriculture, Forest Service, Rocky Mountain Research Station, Fort Collins, CO, 428 p. 74.

Cea, L., Puertas, J., Pena, L., 2007. Velocity measurements on highly turbulent free surface flow using ADV. Experiments in Fluids, 42, 3, 333-348.

Dey, S., Barbhuiya, A.K., 2004. Clear-water scour at abutments in thinly armored beds. Journal of Hydraulic Engineering, 130, 7, 622-634.

Dey, S., Raikar, R., 2007. Clear-water scour at piers in sand beds with an armor layer of gravels. Journal of Hydraulic Engineering, 133, 703-711.

Ettema, R., Braileanu, F., Muste, M., 2000. Method for estimating sediment transport in ice-covered channels. Journal of Cold Regions Engineering, 14, 3, 130-144.

Ettema, R., Kempema, E.W., 2012. River ice effects on gravel bed channels. In: Church, M., Biron, P.M., Roy, A.G. (Eds.): Gravel-Bed Rivers: Processes, Tools, Environments. Wiley, pp. 523-540.

Froehlich, D.C., 1995. Armor limited clear water construction scour at bridge. Journal of Hydraulic Engineering, ASCE 121, 490-493.

Guo, J., 2012. Pier scour in clear water for sediment mixtures. Journal of Hydraulic Research, 50, 1, 18-27.

Hager, W., 1999. Wastewater Hydraulics: Theory and Practice. Springer, Berlin, New York.

Hains, D.B., Zabilansky, L.J., (2004). Laboratory test of scour under ice: Data and preliminary results. U.S. Army Engineer Research and Development Center, Cold Regions Research and Engineering Laboratory, Hanover, New Hampshire, Technical Report TR-04-9 (http://www.crrel.usace.army. mil/techpub/CRREL_Reports/reports/TR04-9.pdf).

Hains, D., Zabilansky, L.J., Weisman, R.N., 2004. An experimental study of ice effects on scour at bridge piers. In: Cold Regions Engineering and Construction Conference and Expo, Edmonton, Alberta, 16-19 May 2004.

Khwairakpam, P., Ray, S.S., Das, S., Das, R., Mazumdar, A., 2012. Scour hole characteristics around a vertical pier under clear water scour conditions. ARPN J. Eng. Appl. Sci, 7, 6, 649-654.

Kothyari, U.C., Garde, R.C.J., Ranga Raju, K.G., 1992. Temporal variation of scour around circular bridge piers. Journal of Hydraulic Engineering, 118, 8, 1091-1106.

Li, S.S., 2012. Estimates of the Manning's coefficient for icecovered rivers. In: Proceedings of the Institution of Civil Engineers-Water Management, Vol. 165, No. 9, pp. 495505. Thomas Telford Ltd.
Mao, L., Cooper, J., Frostick, L., 2011. Grain size and topographical differences between static and mobile armour layers. Earth Surface Processes and Landforms, 36, 10, 13211334.

Mays, L.W. (Ed.), 1999. Hydraulic Design Handbook. McGraw-Hill Professional Publishing, New York.

Melville, B.W., Raudkivi, A.J., 1977. Flow characteristics in local scour at bridge piers. Journal of Hydraulic Research, $15,4,373-380$.

Melville, B.W., Sutherland, A.J., 1988. Design method for local scour at bridge piers. Journal of Hydraulic Engineering, 114, $10,1210-1226$.

Melville, B.W., Coleman, S.E., 2000. Bridge Scour. Water Resources Publications.

Muzzammil, M., Gangadhariah, T., 2003. The mean characteristics of horseshoe vortex at a cylindrical pier. Journal of Hydraulic Research, 41, 3, 285-297.

Raudkivi, A.J., Ettema, R., 1983. Clear-water scour at cylindrical piers. Journal of Hydraulic Engineering, 109, 3, 338350.

Raudkivi, A.J., Ettema, R., 1985. Scour at cylindrical bridge piers in armored beds. J. Hydraul. Eng., 111, 4, 713-731.

Richardson, E.V., Harrison, L.J., Richardson, J.R., Davis, S.R., 1993. Evaluating Scour at Bridges. Report No. HEC 18. 2nd edition. Federal Highway Administration, Washington, DC.

Sui, J., Wang, D., Karney, B., 2000. Sediment concentration and deformation of riverbed in a frazil jammed river reach. Canadian Journal of Civil Engineering, 27, 6, 1120-1129.

Sui, J., Wang, J., Yun, H.E., Krol, F., 2010. Velocity profiles and incipient motion of frazil particles under ice cover. International Journal of Sediment Research, 25, 1, 39-51.

Török, G.T., Baranya, S., Rüther, N., Spiller, S., 2014. Laboratory analysis of armor layer development in a local scour around a groin. In: Proceedings of the International Conference on Fluvial Hydraulics River Flow. EPFL, Lausanne, Switzerland, pp. 3-5.

Wang, J., Shi, F., Chen, P., Wu, P., Sui, J., 2015. Impacts of bridge abutments on the critical condition for initiation of ice cover - an experimental study. Journal of Hydrology and Hydromechanics, 63, 4, 327-333.

Wang, J., Hua, J., Sui, J., Wu, P., Liu, L., Chen, P., 2016. The impacts of bridge pier on ice jam evolution - an experimental study. Journal of Hydrology and Hydromechanics, $64,1,75-82$.

Wu, P., Hirshfield, F., Sui, J., Wang, J., Chen, P.P., 2014. Impacts of ice cover on local scour around semi-circular bridge abutment. Journal of Hydrodynamics, 26, 1, 10-18.

Wu, P., Hirshfield, F., Sui, J., 2015. Armour layer analysis of local scour around bridge abutments under ice cover. River Research and Applications, 31, 6, 736-746.

Zabilansky, L.J., Hains, D.B., Remus, J.I., 2006. Increased bed erosion due to ice. In: Current Practices in Cold Regions Engineering, pp. 1-12.

Zhang, H., Nakagawa, H., Mizutani, H., 2012. Bed morphology and grain size characteristics around a spur dyke. International Journal of Sediment Research, 27, 2, 141-157.

Received 16 April 2018 Accepted 23 July 2018 